\title{
Study on Application of BOM in Hydraulic Torque Converter Production Workshop MES
}

\author{
Yuexin Yang ${ }^{1, a}$, Gongchang Ren ${ }^{2, b}$ Qiang Zhang ${ }^{2, c}$ \\ ${ }^{1}$ College of Electrical and Information Engineering, Shaanxi University of Science \& Technology, \\ Xi'an 710021,China \\ ${ }^{2}$ College of Mechanical and Electrical Engineering, Shaanxi University of Science \& Technology, \\ Xi'an 710021,China \\ àangyuexin@sust.edu.cn, b rengc@sust.edu.cn, ${ }^{\mathrm{c}}$ zhangqiang@sust.edu.cn
}

Keywords: BOM, hydraulic torque converter, MES, database

Abstract. BOM database is designed through the analysis of the actual situation of the production workshop of the torque converter and the demand of enterprise. This paper analyzes scheduling management module, material distribution management module, real-time monitoring module and management module in the hydraulic torque converter production workshop MES. The table structure of BOM database is determined. Finally, the application of BOM database in MES is proposed.

\section{Introduction}

BOM (bill of material), is refers to the product needed parts list and structure. Specifically, BOM is the description file of the product structure. It shows that the product components, a need of the subordinate components number of sub components, the relationship between parts until the raw materials, and each assembly.

With the rapid development of manufacturing industry, the market competition is more and more intense, the enterprises attach great importance to cost control, efficient capacity utilization. The production process is actually accounting capacity, planning and scheduling, production planning, capacity reintegration, and plans to produce a process.BOM plan row all core data of production to reduce the production cycle of the products, to ensure that the customer order delivery plays a strong role, and BOM data accuracy is cost can can effectively control the fundamental guarantee.

\section{Application of BOM in MES of hydraulic torque converter}

The scientific nature of the $\mathrm{BOM}$ architecture and the rationality of the $\mathrm{BOM}$ process is the premise of ensuring the integrity and accuracy of the BOM data. The following is the application of BOM in each stage of production:

(1).The production data preparation phase: In different manufacturing industries, the structure and composition of BOM is different. Product structure tree will be different because of different needs, so To maintain the real-time, integrity and correctness of BOM information is the key to improve the production efficiency of enterprises. Before the production of the enterprise, the production planning department must define the product structure tree in the way of the product structure tree to the BOM database. In order to ensure that each department can get a specific BOM data each component of the information must be input to the database.

(2).Planning scheduling phase: When the enterprise receives the order, the production management department in accordance with the order of delivery deadlines and production line of the actual situation to arrange production schedule. Planning scheduling is affected by the inventory information of components and other raw materials, the impact of the BOM data information. Through the selection of the optimal scheduling scheme to produce, so as to ensure on-time delivery.

(3).Material requirement planning phase: The material management department is responsible for the preparation of materials and the management of inventory in the whole manufacturing system. When the production plan scheduling, the system will generate the various processes of the material demand plan.Material management department with reference to BOM information to 
determine the requirements of various materials, and then the material management department to determine the requirements of the various materials to carry out the preparatory work of the material to ensure that there will be no shortage of material.

(4).Material purchasing phase: The lean production mode requires the enterprise's purchasing department to be served in the time that is needed. Good procurement system can not only reduce the complexity of the procurement process, but also can reduce the unnecessary procurement costs. BOM information is the most important key to the purchasing department. Procurement department through the BOM information can be timely to buy the right amount of material, to avoid the phenomenon of excess inventory or insufficient inventory.

\section{Establishment of BOM in hydraulic torque converter MES}

In summary, the BOM of hydraulic torque converter MES is composed of four parts (parts BOM, process $\mathrm{BOM}$, material $\mathrm{BOM}$, quality $\mathrm{BOM}$ ). Combined with hydraulic torque converter production, taking into account the different types of parts (self-made parts, purchased parts, standard parts) attributes constitute different, BOM dispersed to three data tables to describe.The BOM form as shown in Figure 1.

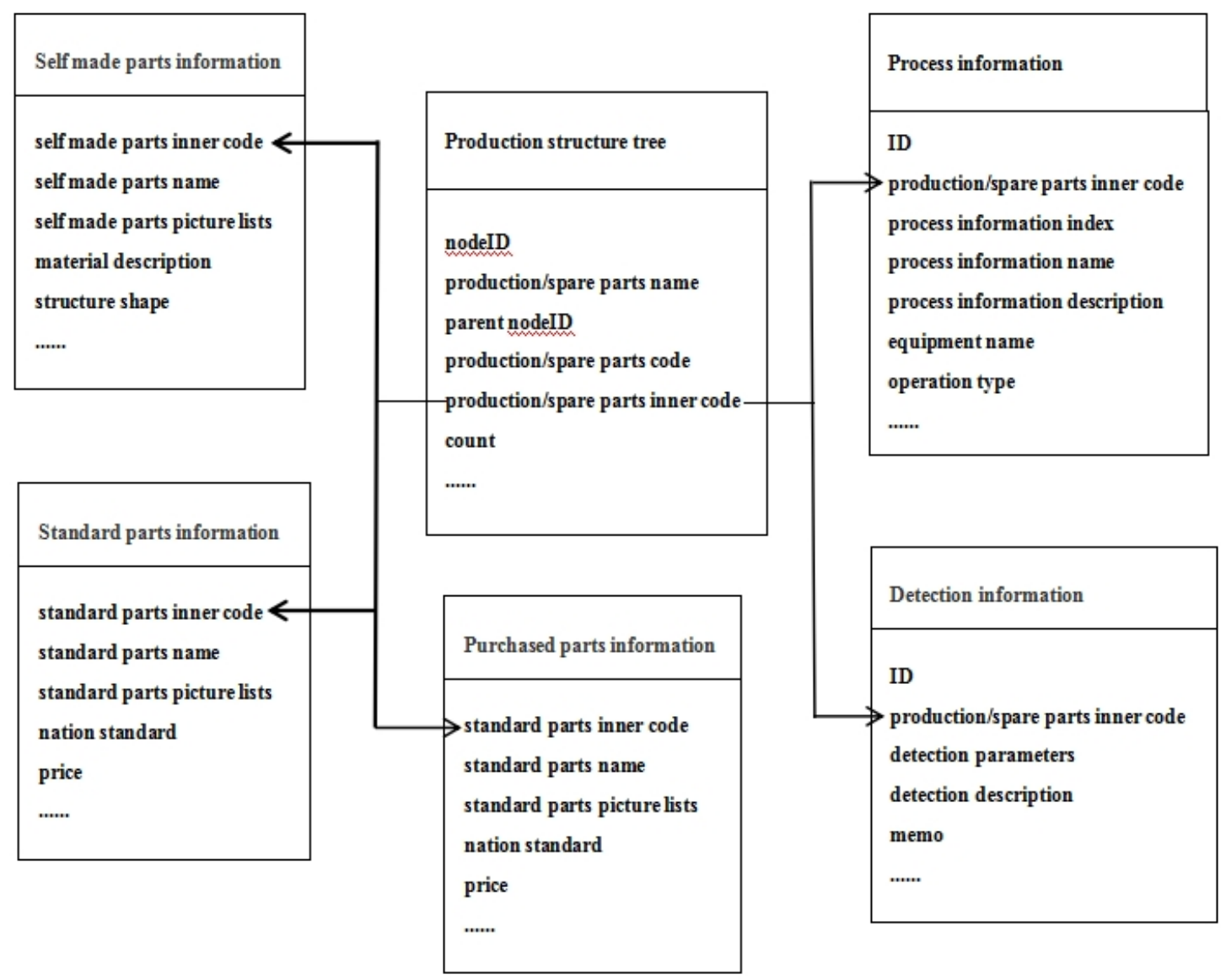

Fig1.Table structure and corresponding relation of $\mathrm{BOM}$ database

The description of the various data tables in BOM are as follows.

Product structure tree table: the table is the core of the BOM. The product structure tree list is to describe the tree structure information of all models of the hydraulic torque converter.Through the contact between the tables to obtain production process information, self-made parts information, information of standard parts, purchased parts information and the quality detection information. The attributes of the product structure tree table include: nodeID(used to represent a node), nodeName(A name for a product or component represented by a node), parentID(Unique identifier for the parent node of the node), count, nodeCode(product / component code), innerCode(the inner code of product/ component). 
All models of the product and components of the product information are stored in the product structure tree table. The node ID for each record is GUID(globally unique identifier, ID card numbers by the binary unique identification number for each card and only CPU digital clock generates a 16 byte. To ensure the value, as a record of ID primary key only).In product structure tree table, the parentID attribute value of the product model record is null, the parentID attribute value of the component record is the unique identifier of the type record that the component belongs to, The parentID attribute value of the part record is the unique identifier of the component record that is part belongs to.The role of count attribute is to reflect the number of components and the number of parts contained in the model.

In the product structure tree table there are two important attributes: nodeCode and innerCode.The attribute nodeCode reflects the relationship between the product and the assembly and the assembly of the parts. Types of code for 2 digits, for example the nodeCode of A type of hydraulic torque is 01 ; Parts of the code for the 4 digits, the first two is belongs to the types of code, such as a hydraulic variable converter belongs to the parts of the code according to the assembly sequence coding respectively 0101 0106; 6 digit code parts. The first four parts of code, including a hydraulic variable torque converter pump components round subordinate parts of the code from the beginning of 010101.

Because of the product parts in accordance with the source of the parts is divided into self-made parts, purchased parts and standard parts. There are different types of products with the same parts in the product, in order to reduce the redundant parts information in the BOM database, the product structure tree table adds an attribute innerCode. The attribute innerCode is an important attribute of the product. Through the attribute innerCode with self-made parts information table, the standard parts information table, purchased parts information table, information process table and detection information table established relationship. According to the hydraulic torque converter product type, quantity, types contained in the number of components and parts in the self-made parts, purchased parts and standard parts accounted for the proportion of to set code encoding format.

Table 1 the product structure tree table code encoding partition table

\begin{tabular}{|c|c|c|}
\hline index & type & coding range \\
\hline 1 & production model & $0001 \sim 0099$ \\
\hline 2 & component & $0101 \sim 0999$ \\
\hline 3 & self made parts & $1001 \sim 4999$ \\
\hline 4 & standard parts & $5001 \sim 6999$ \\
\hline 5 & purchased parts & $7001 \sim 8999$ \\
\hline 6 & reserve & $9001 \sim 9999$ \\
\hline
\end{tabular}

Purchased parts information table: the table holds the information of non-standard parts required for outsourcing in the process of production.

Standard parts information table: the table holds the parts the information of standard parts required in the production process.

Self made information table: The table holds all self processed parts information needed in the production process.

Process information table: The table holds the process information for all models of products produced by the enterprise, process information of components and Process information of self made parts.

Test information table: the table holds parameter information for all types of product to be detected.

\section{Application of BOM in hydraulic torque converter MES}

The product structure tree table in the BOM database can quickly obtain the number of three types of parts(purchased parts, self made parts and standard parts) needed to produce a particular product.The quantity of purchased parts from the MES in the name of the code through the attribute of the products / parts code encoding, you can know the part of code is 6 digits, and the first two parts of the model. At the same time, self-made parts of code for '1001' '4999', eventually obtaining a type 
hydraulic torque converter contains the self-made parts name and number. By changing the query conditions can obtain a type hydraulic torque converter contains different types of parts and quantity information. Through the quantitative information in the hydraulic torque converter workshop scheduling and procurement management provide the required production quantity and the need to purchase parts and standard parts.

The hydraulic torque converter workshop real-time monitoring system is an important part of hydraulic torque converter production workshop MES. Through for production workshop equipment information, personnel information, product information, information detection real-time acquisition, combined with the BOM database process information, information detection can timely access to detailed information on a station equipment, process information. At the same time, real-time monitoring system in the background according to the BOM database detection information table to the comparison from the workshop production of products and components of real-time detection information, to real-time judgment of products or components is qualified or not. At the same time, the related records written to the database, for the future, the qualified rate of equipment efficiency and statistical data to support.

\section{Conclusions}

Combined with hydraulic variable to the actual situation of converter production workshop, and analysis of enterprise for positioning of MES and the established hydraulic margin is bom database can satisfy the requirements of the application of the hydraulic torque converter workshop MES for scheduling management, material distribution management and real-time monitoring function module. Greatly improve the enterprise production efficiency, reduce the cost of enterprise operation, to make the maximum profit of the enterprise.

\section{Acknowledgments}

This work was financially supported by Shaanxi province of China science and technology research and development project (No.2014 GY2-04).

\section{References}

[1]Jackson, Kevin; Roth, Christian; De Freitas, Roberto Resque.A framework for selecting the mos $\mathrm{t}$ appropriate Manufacturing Execution System (MES) for the metals industry.AISTech - Iron and Steel Technology Conference Proceedings, v 2, p 2473-2485, 2013, AISTech 2013 - Proceedings o $\mathrm{f}$ the Iron and Steel Technology Conference.

[2]Cavina, N. ; Corti, E.; Marcigliano, F.; Olivi, D.; Poggio, L. Control-oriented models for real-ti me simulation of automotive transmission systems. Oil and Gas Science and Technology, v 70, n 1, p 67-90, 2015.

[3]Schumann, Andreas.MES - Integrated production control for batch plants. European Control Co nference, ECC 1999 - Conference Proceedings, p 4830-4835, March 24, 2015

[4]Kucharska, Edyta ; Grobler-Dbska, Katarzyna; Gracel, Jaros\&lstrok;aw; Jagodziski, Mieczys\&l strok;aw.Idea of impact of ERP-APS-MES systems integration on the effectiveness of decision ma king process in manufacturing companies. Communications in Computer and Information Science, v 521, p 551-564, 2015.

[5]Zhang, Mingxin; He, Qiang; Gong, Jianxing. Research on BOM based composable modeling me thod. Proceedings of SPIE - The International Society for Optical Engineering, v 8784, 2013, Fifth International Conference on Machine Vision, ICMV 2012: Algorithms, Pattern Recognition and Ba sic Technologies. 